\title{
1 Impact of the COVID-19 pandemic on the malaria burden in northern Ghana: Analysis
}

3 Anna-Katharina Heuschen ${ }^{1 *}$, Alhassan Abdul-Mumin ${ }^{2}$, Martin Nyaaba Adokiya $^{3}$, Guangyu

$4 \quad$ Lu $^{4}$, Albrecht Jahn ${ }^{1}$, Oliver Razum ${ }^{5}$, Volker Winkler ${ }^{1}$, Olaf Müller ${ }^{1}$

5

$6 \quad$ * Corresponding author

81 Institute of Global Health, Medical School, Ruprecht-Karls-University Heidelberg, $9 \quad$ Germany

2 University for Development Studies, School of Medicine, Department of Pediatrics and Child Health, Tamale, Ghana

3 University for Development Studies, School of Public Health, Department of Epidemiology, Biostatistics and Disease Control, Tamale, Ghana Health, Bielefeld University, Germany

Abstract

Introduction: The COVID-19 pandemic and its collateral damage severely impact

20 health systems globally and risk to worsen the malaria situation in endemic countries. Malaria

21 is a leading cause of morbidity and mortality in Ghana. This study aims to analyze routine

22 surveillance data to assess possible effects on the malaria burden in the first year of the

23 COVID-19 pandemic in the Northern Region of Ghana.

NOTE: This preprint reports new research that has not been certified by peer review and should not be used to guide clinical practice. 
25 System II (DHIMS2) of the Northern Region of Ghana were analyzed. Overall outpatient

26 department visits and malaria incidence rates from the years 2015 to 2019 were compared to

27 the corresponding data of the year 2020.

28 Results: Compared to the corresponding periods of the years 2015 to 2019, overall

29 visits and malaria incidence in pediatric and adult outpatient departments in northern Ghana

30 decreased in March and April 2020, when major movement and social restrictions were

31 implemented in response to the pandemic. Incidence slightly rebounded afterwards in 2020

32 but stayed below the average of the previous years. Data from inpatient departments showed

33 a similar but more pronounced trend when compared to outpatient departments. In pregnant

34 women, however, malaria incidence in outpatient departments increased after the first

35 COVID-19 wave.

36 Discussion: The findings from this study show that the COVID-19 pandemic affects

37 the malaria burden in health facilities of Ghana, with declines in in- and outpatient rates.

38 Pregnant women may experience reduced access to intermittent preventive malaria treatment

39 and insecticide treated nets, resulting in subsequent higher malaria morbidity. Further data

40 from other African countries, particularly on community-based studies, are needed to fully

41 determine the impact of the pandemic on the malaria situation.

\section{Keywords}

44 COVID-19, pandemic, malaria, sub-Saharan Africa, Ghana, Northern Region, health 45 information system, surveillance, morbidity, routine data

\section{Introduction}


48 Malaria remains one of the leading causes of morbidity and mortality in sub-Saharan

49 Africa (SSA). It is responsible for nearly one quarter of all under five childhood deaths in this 50 region $(1,2)$.

51 The global spread of the coronavirus disease 2019 (COVID-19) was declared a Public

52 Health Emergency of International Concern, which is the highest level of alarm, at the end of

53 January 2020 (3). Many African governments responded rapidly to this threat by

54 implementing control measures even before first cases were detected in their countries,

55 comprising border closures, movement restrictions, social distancing and school closures (4).

56 By November 2021, there were nearly 6.2 million COVID-19 cases reported from the WHO

57 African Region, with about 152,000 deaths, mostly from the southern and northern rims of

58 the continent (5). In the global context, SSA accounts for only about $2.5 \%$ and $3 \%$ of the 59 overall reported COVID-19 morbidity and mortality, respectively, while it is home to $17 \%$ of 60 the global population (6-8). This may be explained by factors such as a younger population,

61 hotter climate, interferences with other infectious diseases, and especially lack of diagnostics 62 and underreporting $(9,10)$. Ghana is among the countries with the highest reported COVID-

6319 cases $(130,920)$ and deaths $(1,209)$ in western and central SSA, as of November $2021(8)$.

64 COVID-19 vaccinations started in February 2021 but coverage in Ghana is still low with only

$65 \quad 2.7 \%$ of the population fully vaccinated by November 2021 (11).

66 The socio-economic disruptions associated with the disease and the preventive 67 measures present huge challenges for health systems and whole societies, especially in low-

68 and middle income countries (12). In the highly malaria-endemic African countries, the 69 progress made in malaria control during the last two decades is feared to be reversed by the 70 side effects of the COVID-19 pandemic $(13,14)$.

71 This study aims to compare the malaria burden in the Northern Region of Ghana in 72 the first year of the pandemic to previous years to assess whether a reversal indeed occurred. 


\section{Methods}

\section{Study area}

76 Ghana, with its population of about 31 million, lies in western SSA and has a

77 relatively well functioning health care system $(15,16)$. Ghana is divided into 16

78 administrative regions. The Northern Region, with its capital city Tamale, had a population of

791.9 million in 2020. The socio-economic situation of the Northern Region is below the

80 national average of the country and the region has the highest rate of mortality under the age

81 of five years (17). The rainy season in northern Ghana, which is usually associated with an

82 increase in the malaria incidence, lasts from May to October (18).

83 Malaria is highly endemic in Ghana; the country accounts for $2 \%$ of the global

84 malaria morbidity and $3 \%$ of the malaria mortality $(19,20)$. In 2020 , malaria was the cause of

$8534 \%$ of all outpatient attendances (21). Treatment expenditures for common diseases like

86 malaria are covered by a health insurance (22).

87 The first two confirmed COVID-19 cases in Ghana were seen on March 12, 2020; two

88 days later, all public gatherings were banned. Travel restrictions and border closures were

89 implemented on March 22, 2020 and the country's major cities were placed under partial

90 lockdown soon after. Schools were partially reopened on June 21, 2020 and borders were

91 reopened to international airlines on September 21, 2020 (23). In Ghana, effects of the

92 COVID-19 pandemic on malaria control interventions concerned the country's stock of

93 artemisinin-based combination therapies (ACT), the functioning of its insecticide-treated

94 mosquito net (ITN) routine distribution, and the overall access to primary health care services

95 and facilities (24).

96

\section{Study design and data}


medRxiv preprint doi: https://doi.org/10.1101/2021.11.29.21266976; this version posted November 29, 2021. The copyright holder for this preprint (which was not certified by peer review) is the author/funder, who has granted medRxiv a license to display the preprint in perpetuity.

It is made available under a CC-BY 4.0 International license .

98

99

100

101

102

103

104

105

106

107

108

109

110

111

112

113

114

115

116

117

118

119

120

\section{Results}

\section{Analysis}

This retrospective observational study uses monthly malaria morbidity data on the overall number of outpatients (interpreted as less severe cases) and inpatients (more severe cases). Additionally, all outpatient visits (including non-malaria related visits) are analyzed.

Cases were extracted from the district health information management system II (DHIMS2) on demographic and health parameters of northern Ghana from January 1, 2015, to December 31, 2020. This system was implemented in 2007 with an update in 2012 and has improved the data quality and completeness since (25).

Malaria diagnosis was based either on the results of rapid diagnostic tests or microscopy. Mid-year population estimates of the Northern Region of Ghana were also provided through the DHIMS2.

The data have been processed with Microsoft Excel Version 16.52 and analyzed with Stata IC Version 16 (Statacorp, College Station, TX, USA). We have calculated and plotted monthly incidence rates of all outpatient visits and confirmed malaria cases for the year 2020 and as a comparison for the years 2015 to 2019 separately and combined using population figures of the Northern Region of Ghana. Additionally, we calculated incidence rate ratios with $95 \%$ confidence intervals (95\% CI) comparing quarterly incidence rates of 2020 versus the combined rates of 2015 to 2019 . The data allowed analyzing children under five years and pregnant women separately using the fraction of the under-five population (14\% of the population) and the fraction of women between 15 and 45 years (23\% of the population) as estimates of the respective population denominators (26).

\begin{tabular}{|c|c|c|}
\hline & Number & Percentage (\%) \\
\hline \multicolumn{2}{|c|}{ outpatient department visits } \\
\hline
\end{tabular}


medRxiv preprint doi: https://doi.org/10.1101/2021.11.29.21266976; this version posted November 29, 2021. The copyright holder for this preprint (which was not certified by peer review) is the author/funder, who has granted medRxiv a license to display the preprint in perpetuity.

It is made available under a CC-BY 4.0 International license .

\begin{tabular}{|l|c|c|}
\hline All & $5,804,910$ & 100 \\
\hline Malaria confirmed & $2,278,296$ & 39 \\
\hline $\begin{array}{l}\text { Malaria confirmed among } \\
\text { children <5 years }\end{array}$ & 454,779 & 20 \\
\hline $\begin{array}{l}\text { Malaria confirmed among } \\
\text { pregnant women }\end{array}$ & 46,693 \\
\hline \multicolumn{2}{|c|}{ hospital-admitted patients } \\
\hline Malaria confirmed & 295,465 \\
\hline $\begin{array}{l}\text { Malaria confirmed among } \\
\text { children <5 years }\end{array}$ & 165,313 \\
\hline \multicolumn{2}{|c|}{100} \\
\hline Total population & $1,842,701$ & 56 \\
\hline Children <5 years* & 257,978 & 100 \\
\hline Women aged 15 to 45* & 423,821 & 14 \\
\hline
\end{tabular}

122 Table 1: Description of the dataset

123

124 Table 1 presents a brief description of the dataset. Altogether 5.8 million outpatient

125 department visits were reported between 2015 and 2020; 39\% of those included a malaria

126 diagnosis. Of all confirmed malaria cases, $20 \%$ were children under the age of five years and

$1272 \%$ were pregnant women. 295,465 patients were hospitalized with diagnosed malaria, $56 \%$

128 of those were children under the age of five years. The mean population of the years from

1292015 to 2020 was $1,842,701$ with $14 \%$ of children under the age of five years and $23 \%$ of

130 women between the age of 15 and 45 considered as of possible childbearing age. 

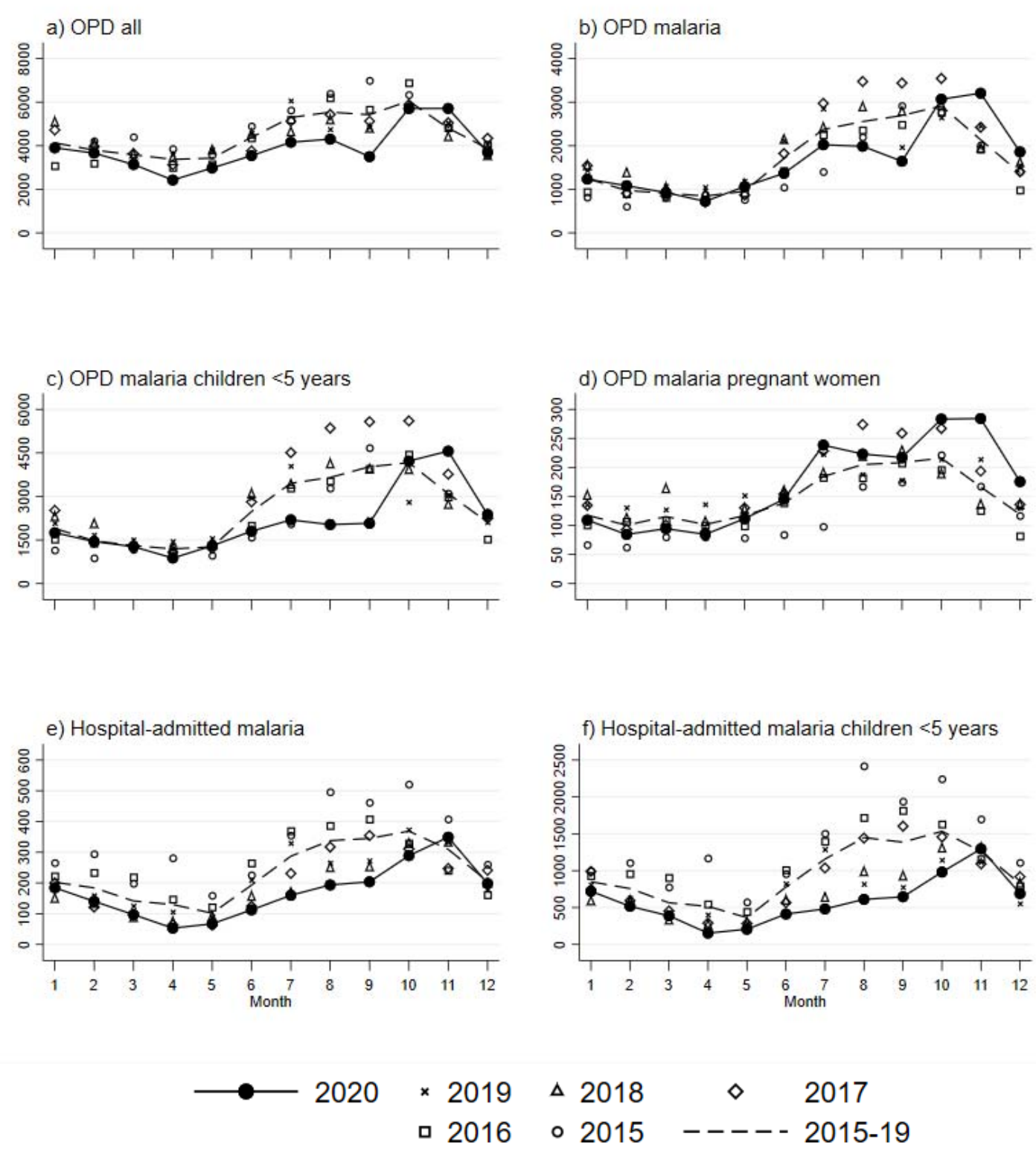

note: different $y$-axis scaling

132 Figure 1: Reported monthly incidence rates per 100,000 of the Northern Region, Ghana for the years 2015 to 2020

Figure 1 presents the incidence rates of the different outcomes reported in the

136 Northern Region of Ghana for the years between 2015 and 2020 separately as well as a combined rate for the period 2015 to 2019. All visits of the outpatient department (OPD) (see

138 Figure 1a), including also non-malaria patients, have experienced a major decline in 
139 March/April 2020, the months where COVID-19 control measures were implemented in the 140 country, and stayed low during the following months. After a further decrease in September 1412020 , the numbers increased again in October 2020 to the levels observed in previous years.

142 This trend is similar but not as pronounced in the general malaria OPD visits (Figure 1b). In 143 children under the age of five years, the decline in accessing OPD malaria health care is 144 stronger, especially from June to September 2020 (Figure 1 c). In pregnant women, however, 145 a different trend with an earlier increase, starting in June and exceeding previous year's 146 levels, can be observed (Figure 1d). The 2020 numbers of the hospitally admitted malaria 147 patients stayed below the previous standards from March to October 2020 (Figure 1e); and in 148 accordance with the OPD figures, this trend is more pronounced in the children under five 149 years population (Figure 1f).

Incidence rate ratios (IRR) depicting quarterly measures comparing the rates of 2020 to the combined rate of the years 2015 to 2019 are presented in table 2. General OPD visits were reduced in the $2^{\text {nd }}$ and $3^{\text {rd }}$ quarters of 2020 compared to the previous years (IRR $3^{\text {rd }}$ quarter 0.736 ) with a return to previous standards at the end of the year. The same applies to

155 the overall malaria cases (IRR 0.742 in the $3^{\text {rd }}$ quarter) but with increases in the $4^{\text {th }}$ quarter 156 (IRR 1.265). Ambulatory malaria cases in children under five experienced stronger 157 reductions compared to previous years with an IRR 0.566 in the $3^{\text {rd }}$ quarter of 2020 . These 158 evolutions are not mirrored by the population of pregnant women with malaria infections, 159 where no major reductions were observed during the first quarters of 2020 compared to 160 previous years but with an earlier increase (IRR 1.481 in the $4^{\text {th }}$ quarter). The situation is 161 slightly different in malaria infected patients admitted to the hospital. The reductions in the $1622^{\text {nd }}$ and $3^{\text {rd }}$ quarters of 2020 are more pronounced (IRR 0.548 for all ages in the $2^{\text {nd }}$ quarter) 163 and the numbers do not fully recover at the end of the year. Again, as for the outpatient 
medRxiv preprint doi: https://doi.org/10.1101/2021.11.29.21266976; this version posted November 29, 2021. The copyright holder for this preprint (which was not certified by peer review) is the author/funder, who has granted medRxiv a license to display the preprint in perpetuity.

It is made available under a CC-BY 4.0 International license .

164 population, this trend is more pronounced in children under five years of age (IRR 0.465 in 165 the $2^{\text {nd }}$ quarter).

166

\begin{tabular}{|c|c|c|c|c|}
\hline Outcome & $\begin{array}{c}\text { IRR }(95 \% \text { CI }) \\
1^{\text {st }} \text { Quarter }\end{array}$ & $\begin{array}{c}\text { IRR }(95 \% \text { CI }) \\
2^{\text {nd }} \text { Quarter }\end{array}$ & $\begin{array}{c}\text { IRR }(95 \% \text { CI }) \\
3^{\text {rd }} \text { Quarter }\end{array}$ & $\begin{array}{c}\text { IRR }(95 \% \text { CI }) \\
4^{\text {th }} \text { Quarter }\end{array}$ \\
\hline \multicolumn{5}{|c|}{ outpatient department visits } \\
\hline All & $\begin{array}{c}0.930 \\
(0.925-0.934)\end{array}$ & $\begin{array}{c}0.800 \\
(0.796-0.804)\end{array}$ & $\begin{array}{c}0.736 \\
(0.732-0.739)\end{array}$ & $\begin{array}{c}1.026 \\
(1.022-1.030)\end{array}$ \\
\hline Malaria & $\begin{array}{c}1.035 \\
(1.026-1.044)\end{array}$ & $\begin{array}{c}0.899 \\
(0.892-0.907)\end{array}$ & $\begin{array}{c}0.742 \\
(0.737-0.746)\end{array}$ & $\begin{array}{c}1.265 \\
(1.258-1.272)\end{array}$ \\
\hline Malaria children $<5$ years & $\begin{array}{c}0.956 \\
(0.937-0.974) \\
\end{array}$ & $\begin{array}{c}0.806 \\
(0.790-0.823)\end{array}$ & $\begin{array}{c}0.566 \\
(0.557-0.575)\end{array}$ & $\begin{array}{c}1.190 \\
(1.176-1.206)\end{array}$ \\
\hline Malaria pregnant women & $\begin{array}{c}0.865 \\
(0.815-0.918) \\
\end{array}$ & $\begin{array}{c}0.957 \\
(0.905-1.011) \\
\end{array}$ & $\begin{array}{c}1.136 \\
(1.091-1.182) \\
\end{array}$ & $\begin{array}{c}1.481 \\
(1.424-1.540) \\
\end{array}$ \\
\hline \multicolumn{5}{|c|}{ hospital-admitted patients } \\
\hline Malaria & $\begin{array}{c}0.799 \\
(0.780-0.817)\end{array}$ & $\begin{array}{c}0.548 \\
(0.531-0.565)\end{array}$ & $\begin{array}{c}0.574 \\
(0.563-0.586)\end{array}$ & $\begin{array}{c}0.946 \\
(0.930-0.962)\end{array}$ \\
\hline Malaria children $<5$ years & $\begin{array}{c}0.749 \\
(0.726-0.773)\end{array}$ & $\begin{array}{c}0.465 \\
(0.445-0.486)\end{array}$ & $\begin{array}{c}0.435 \\
(0.422-0.448)\end{array}$ & $\begin{array}{c}0.820 \\
(0.800-0.839)\end{array}$ \\
\hline
\end{tabular}

167 Table 2: Quarterly incidence rate ratios (IRR) with 95\% confidence intervals (95\% CI)

168 comparing the incidence rates of 2020 with the combined incidence rates of the years 2015 to

1692019

170

171 Discussion

172 Since the beginning of the COVID-19 pandemic, several modelling studies have predicted

173 negative collateral effects on the malaria burden in SSA, considering especially disrupted

174 ITN campaigns and a limited access to antimalarial drugs. The study team of Weiss et al.

175 created nine scenarios for different reductions of ITN coverage and access to antimalarial

176 medication as well as regarding effects on malaria morbidity and mortality. As no ITN mass

177 campaigns were scheduled for 2020 in Ghana, the worst-case scenario would have been a

178 decline in access to antimalarials by $75 \%$ resulting in an increase of malaria morbidity and

179 mortality by $12.6 \%$ and $54.6 \%$, respectively (13). Overall, the predicted public health

180 relevant effects of the COVID-19 pandemic on malaria include shared clinical disease

181 manifestations leading to diagnostical challenges, disruptions of the availability of curative

182 and preventive malaria commodities, significant effects on malaria programs, and in

183 particular reduced access to malaria health services and health facilities in general (27). 
In this study, we observed a slight but significant decline in malaria incidence during the $2^{\text {nd }}$ and $3^{\text {rd }}$ quarter of 2020 (April to September), and only a rebound to the average levels

of previous years at the end of 2020. This pattern was visible in both, outpatient and inpatient

and adults, where the reductions were also observed in both groups, but were more marked in

children under five years of age. The marked decline in March/April 2020 can be explained

by the extensive restrictions of movement and gathering and early stay-at-home advices for

COVID-19-like symptoms unless these get severe. Such measures have likely supported the

hesitancy to visit health facilities during the pandemic, which in turn poses a major risk for

more severe malaria manifestation, patients were still brought to health facilities and

hospitalized, despite the pandemic. The findings from this analysis support the hypothesis,

that the reported malaria burden in health facilities will shrink due to the effects of the

COVID-19 pandemic in highly malaria-endemic countries (Heuschen et al. 2021). They also

Leone, Uganda and the Democratic Republic of the Congo (29-32).

The distinct decrease of OPD visits in the health facilities of northern Ghana in

203 September 2020 may also be explained by unusual heavy floods that started mid-August and

204 could have further complicated the access to health services. Flooded land is a favorable

205 habitat for Anopheles mosquitos, the malaria vector, what could have led to the observed

206 increases of malaria incidence in October 2020.

208 After a decline in reported malaria cases in April 2020, malaria figures have rebounded 
209 rapidly in this population and reached even higher levels compared to previous years. The

210 most likely explanation of such an opposite trend would be the hesitancy of pregnant women

211 to visit health facilities. This is probably due to the fear of getting infected with COVID-19,

212 combined with initial disruptions of the provision of intermittent preventive treatment in

213 pregnancy (IPTp) to women in antenatal care (ANC) services as well as the disruption of

214 routine distribution of ITNs (33). The disrupted access to and delivery of ANC services is

215 likely to explain the malaria case trend in April. However, without IPTp and ITNs, more

216 women were at risk for malaria thereafter, which can explain the subsequent rise in malaria

217 cases over the following months. Also, many pregnant women probably have sought the

218 missed ANC after the initial movement restrictions were lifted with subsequent malaria

219 diagnosis.

220 Ghana had already achieved high levels of ITN coverage, and no ITN mass campaign

221 was planned for 2020 (12). However, the routine distribution of ITNs, which is usually done

222 in health facilities during ANC sessions and in primary schools, needed to be adapted to the

223 COVID-19 measures, which included school closure from March 2020 until January 2021

$224(34,35)$. Also the seasonal malaria chemoprevention intervention for children and the annual

225 indoor residual spraying of insecticides, which both require physical contact between the

226 health workers and the community, needed to be modified $(36,37)$. As another consequence

227 of the COVID-19 pandemic, the provision of rapid diagnostic tests for malaria is fragile,

228 which may have led to under-diagnosis of cases (38). Finally, reports of hesitancy to visit

229 health facilities due to fear of getting infected with COVID-19 are still common $(33,38)$.

230 Last but not least, the malaria health care workers capacities were limited due to frequent

231 reassignments to the control of COVID-19, to stigmatization or absence following

232 quarantine, or to the development of COVID-19 disease or even death $(13,35,39)$. 
medRxiv preprint doi: https://doi.org/10.1101/2021.11.29.21266976; this version posted November 29, 2021. The copyright holder for this preprint (which was not certified by peer review) is the author/funder, who has granted medRxiv a license to display the preprint in perpetuity.

It is made available under a CC-BY 4.0 International license .

233 This study has strengths and limitations. A strength of the study is that the data

234 represent a whole year of follow-up into the pandemic, which provides a more

235 comprehensive picture of the effects compared to the previous studies with much shorter

236 study periods. Limitations are that the surveillance system itself may have been affected by

237 the pandemic, with a bias in the reported numbers. Moreover, it is not clear if the quality of

238 surveillance data is fully comparable during the five years observed. Finally, much more

239 people with malaria symptoms may have switched to self-medication during the pandemic,

240 which may also have an albeit unknown effect on the malaria figures.

241

242 In conclusion, this study shows that the COVID-19 pandemic has been accompanied

243 by a reduced malaria incidence in northern Ghana's health facilities. Further data from other

244 African countries and in particular data from community-based studies are needed to fully

245 judge the impact of the pandemic on the global malaria situation.

247 Declarations

248 Ethics approval and consent to participate

249 No ethical approval and consent to participate was required as only secondary data 250 have been used.

252 Consent for publication

253 No consent for publication was required (only secondary data used).

254

255 Availability of data and material

256 The datasets used and/or analyzed in this study are available from the corresponding

257 author on reasonable request. 
medRxiv preprint doi: https://doi.org/10.1101/2021.11.29.21266976; this version posted November 29, 2021. The copyright holder for this preprint (which was not certified by peer review) is the author/funder, who has granted medRxiv a license to display the preprint in perpetuity.

It is made available under a CC-BY 4.0 International license .

259 Competing interests

260 The authors declare that they have no competing interests.

261

262 Funding

263 Anna-Katharina Heuschen acknowledges the support by the Else Kröner-Fresenius-

264 Stiftung within the Heidelberg Graduate School of Global Health.

265

266

Authors' contributions

267

AAM and MNA were responsible for the data collection. AH, VW and OR performed

268 the data analysis. AH wrote the first draft under the supervision of OM, AAM and MNA

269 supported the data interpretation. All authors read, reviewed and approved the final

270 manuscript.

271

272

Acknowledgements

273 We acknowledge financial support by the Else Kröner-Fresenius-Stiftung within the

274 Heidelberg Graduate School of Global Health, by Deutsche Forschungsgemeinschaft within

275 the funding programme Open Access Publishing, by the Baden-Württemberg Ministry of

276 Science, Research and the Arts and by Ruprecht-Karls-Universität Heidelberg.

278 Bibliography

279 1. Global Burden of Disease, Viz Hub [Internet]. University of Washington. 2021 [cited

280 30.04.2021]. Available from: https://vizhub.healthdata.org/gbd-compare/.

$2812 . \quad$ Müller O. Malaria in Africa: challenges for control and elimination in the 21st

282 century: Peter Lang Frankfurt; 2011.

283 3. WHO. Timeline of WHO's response to COVID-19. 2021.

284 4. WHO. Strategic Response to COVID-19 in the WHO African Region. 2021.

285 5. WHO. COVID-19 Situation update for the WHO African Region 14.10.2020. External

286 Situation Report [Internet]. 2020; 33. Available from: 
287 https://apps.who.int/iris/bitstream/handle/10665/336116/SITREP_COVID-

288 19_WHOAFRO_20201014-eng.pdf.

289 6. Boum Y, Bebell LM, Bisseck A-CZ-K. Africa needs local solutions to face the COVID-19

290 pandemic. The Lancet. 2021;397(10281):1238-40.

291 7. WHO. Coronavirus (COVID-19), Africa2021. Available from:

292 https://www.afro.who.int/health-topics/coronavirus-covid-19.

293 8. Johns Hopkins University. COVID-19 Global Map 2021 [updated 26.05.2021.

294 Available from: https://coronavirus.jhu.edu/map.html.

$2959 . \quad$ Maeda JM, Nkengasong JN. The puzzle of the COVID-19 pandemic in Africa. Science. 296 2021;371(6524):27-8.

297 10. Adams J, MacKenzie MJ, Amegah AK, Ezeh A, Gadanya MA, Omigbodun A, et al. The

298 Conundrum of Low COVID-19 Mortality Burden in sub-Saharan Africa: Myth or Reality?

299 Global Health: Science and Practice. 2021.

300 11. Our World in Data. Coronavirus (COVID-19) Vaccinations. In: University of Oxford, 301 editor. 2021.

302 12. WHO. World malaria report 2020: 20 years of global progress and challenges.2020

303 11.05.2020. Available from: https://www.who.int/teams/global-malaria-

304 programme/reports/world-malaria-report-2020.

305 13. Weiss DJ, Bertozzi-Villa A, Rumisha SF, Amratia P, Arambepola R, Battle KE, et al.

306 Indirect effects of the COVID-19 pandemic on malaria intervention coverage, morbidity, and 307 mortality in Africa: a geospatial modelling analysis. Lancet Infect Dis. 2020.

308 14. Sherrard-Smith E, Hogan AB, Hamlet A, Watson OJ, Whittaker C, Winskill P, et al. The 309 potential public health consequences of COVID-19 on malaria in Africa. Nat Med.

310 2020;26(9):1411-6.

311 15. UNDP. Ghana: United Nations Development Programme; 2021 [Available from:

312 https://www.gh.undp.org/content/ghana/en/home/countryinfo.html.

313 16. The World Bank. Ghana, Total population 2021 [Available from:

314 https://data.worldbank.org/indicator/SP.POP.TOTL?locations=GH.

315 17. UNICEF. Child Protection Baseline Research: Northern Regional Profile2018.

316 Available from: https://www.unicef.org/ghana/media/2896/file/CP\%20Profile\%20-

317 \%20Northern\%20Region.pdf.

318 18. Climate Service Center. Climate Fact Sheet Benin-Ghana-Togo. 2015.

319 19. World Health Organization. World malaria report 2020

32020 years of global progress \& challenges 2020 . Available from:

321 https://www.who.int/publications/i/item/9789240015791.

322 20. United Nations. Ghana: Human Development Indicators 2020 [Available from:

323 http://hdr.undp.org/en/countries/profiles/GHA.

324 21. Ghana Health Service. National Malaria Control Programme 2020 [Available from:

325 https://www.ghanahealthservice.org/ghs-subcategory. php?cid=4\&scid=41.

326 22. Ghana Statistical Service. Ghana Malaria Indicator Survey 20192020. Available from:

327 https://dhsprogram.com/pubs/pdf/MIS35/MIS35.pdf.

328 23. Ghana Health Service. COVID-19: Ghana's Outbreak Response Management Update

329 Accra2020 [Available from: https://www.ghanahealthservice.org/covid19/.

330 24. RBM Partnership to End Malaria. CRSPC Country Tracker to Mitigate the Effect of

331 COVID-19 on Malaria: UNOPS; 2020 [updated 03.12.2020. Available from:

332 https://endmalaria.org/sites/default/files/CRSPC\%20Country\%20Tracker\%20to\%20Mitigate

333 \%20the\%20Effect\%20of\%20COVID-19\%20on\%20Malaria\%20-3\%20December\%202020.pdf. 
334 25. Adokiya MN, Awoonor-Williams JK, Beiersmann C, Müller O. Evaluation of the

335 reporting completeness and timeliness of the integrated disease surveillance and response

336 system in northern Ghana. Ghana Med J. 2016;50(1):3-8.

337 26. United Nations DoEaSA, Population Division,. World Population Prospects 2019,

338 Online Edition. 2019.

339 27. Heuschen A-K, Lu G, Razum O, Abdul-Mumin A, Sankoh O, von Seidlein L, et al. Public

340 health relevant consequences of the COVID-19 pandemic on malaria in sub-Saharan Africa:

341 A scoping review. medRxiv. 2021:2021.06.17.21258914.

342 28. Roberts L. Pandemic's fallout on malaria control appears limited so far. Science.

343 2020;369(6506):892.

344 29. Buonsenso D, lodice F, Cinicola B, Raffaelli F, Sowa S, Ricciardi W. Management of

345 malaria in children under 5-years-old during COVID-19 pandemic in Sierra Leone: a lesson

346 learned? medRxiv. 2020:2020.11.04.20225714.

347 30. Bell D, Hansen KS, Kiragga AN, Kambugu A, Kissa J, Mbonye AK. Predicting the Impact

348 of COVID-19 and the Potential Impact of the Public Health Response on Disease Burden in

349 Uganda. Am J Trop Med Hyg. 2020;103(3):1191-7.

350 31. Burt JF, Ouma J, Lubyayi L, Amone A, Aol L, Sekikubo M, et al. Indirect effects of

351 COVID-19 on maternal, neonatal, child, sexual and reproductive health services in Kampala,

352 Uganda. BMJ Global Health. 2021;6(8):e006102.

353 32. Hategeka C, Carter SE, Chenge FM, Katanga EN, Lurton G, Mayaka SM-N, et al.

354 Impact of the COVID-19 pandemic and response on the utilisation of health services in

355 public facilities during the first wave in Kinshasa, the Democratic Republic of the Congo. BMJ

356 Global Health. 2021;6(7):e005955.

357 33. Moyer CA, Sakyi KS, Sacks E, Compton SD, Lori JR, Williams JEO. COVID-19 is

358 increasing Ghanaian pregnant women's anxiety and reducing healthcare seeking. Int J

359 Gynaecol Obstet. 2021;152(3):444-5.

360 34. Owusu-Akrofi O. In: Programme-Ghana NMC, editor. 2021.

361 35. WHO. Interview with Dr Keziah Malm, Programme Manager, National Malaria

362 Control Programme, Ghana2021. Available from: https://www.who.int/news-room/feature-

363 stories/detail/interview-with-dr-keziah-malm-programme-manager-national-malaria-

364 control-programme-ghana.

365 36. PMI. Key Malaria Spray Campaigns Continue with Adaptations During COVID-192021.

366 Available from: https://www.pmi.gov/key-malaria-spray-campaigns-continue-with-

367 adaptations-during-covid-19-2/.

368 37. USAID. Preventing Malaria in Ghana through Seasonal Malaria

369 Chemoprevention2021. Available from: https://www.ghsupplychain.org/news/preventing-

370 malaria-ghana-through-seasonal-malaria-chemoprevention.

371 38. RBM Partnership to End Malaria. Country Tracker to Mitigate the Effect of COVID-19 372 on Malaria 2021 [Available from:

373 https://endmalaria.org/sites/default/files/CRSPC_Country_Tracker_to_Mitigate_the_Effect

_of_COVID-19_on_Malaria_11_May_2021.pdf.

39. Rogerson SJ, Beeson JG, Laman M, Poespoprodjo JR, William T, Simpson JA, et al.

Identifying and combating the impacts of COVID-19 on malaria. BMC Med. 2020;18(1):239. 